\title{
SOBRE A EMPRESA, A APROPRIAÇÃO DO BUDISMO E A ÊNFASE NA PRODUTIVIDADE: REFLEXÕES A PARTIR DE REPORTAGENS DA REVISTA EXAME
}

\section{THE ENTERPRISE, THE APPROPRIATION OF BUDDHISM AND THE EMPHASIS ON PRODUCTIVITY: REFLECTIONS FROM REPORTS OF EXAME MAGAZINE}

\author{
Natália Nunes da Cunha ${ }^{1}$ \\ ORCID: https://orcid.org/0000-0003-0294-4382 \\ Charles Buchweitz Bergmann ${ }^{2}$ \\ ORCID: https://orcid.org/0000-0001-9022-9543 \\ Marcio Silva Rodrigues ${ }^{3}$ \\ ORCID: https://orcid.org/0000-0002-8810-7077
}

Submissão: 11/05/2020 / Aceito: 20/07/2020.

Resumo: A forte influência do modelo empresarial sobre os humanos e as organizações tem se tornado cada vez mais presente nas sociedades modernas, promovendo o que se compreende como o processo de empresarização. Seguindo estes argumentos, o objetivo deste texto é evidenciar a incorporação de práticas religiosas budistas no espaço empresarial, destacando os impactos que estas vêm sofrendo pela apropriação e distorção em seus princípios. Para desenvolver esta pesquisa de natureza predominantemente qualitativa, analisamos reportagens, retiradas da revista EXAME, que apresentavam conteúdo relacionado ao tema. De maneira geral, a análise das reportagens revela que as empresas estão constantemente se apropriando de alguns conhecimentos budistas com o intuito de aumentar a produtividade e completar as lacunas que elas (empresas) ocasionam.

Palavras-chave: Empresarização; Revista EXAME; Produtividade; Budismo; Meditação.

Abstract: The influence of the business model on humans and organizations has, in effect, become increasingly present in modern societies, promoting whats is understood as the enterprisation process. Following these arguments, the objective of this text is to highlight the incorporation of Buddhist religious practices in the business space, addressing the impact these practices have been suffering due to the appropriation and distortion of its principles. To develop this research of predominantly qualitative nature, we sought to analyze reports, taken from EXAME magazines, that presented content related to the theme. In general, the

\footnotetext{
${ }^{1}$ Acadêmica do Curso de Bacharelado em Administração da Universidade Federal de Pelotas (UFPel)

${ }^{2}$ Acadêmico do Curso de Bacharelado em Administração da Universidade Federal de Pelotas (UFPel)

${ }^{3}$ Professor Adjunto do Departamento de Administração da Universidade Federal de Pelotas (UFPel)
} 
Revista Cadernos de Economia

Universidade Comunitária da Região de Chapecó -Unochapecó

analysis of the reports reveals that companies are constantly appropriating Buddhist practices in order to increase productivity and fill the gaps that they (companies) cause.

Keywords: Enterprisation; EXAME Magazine; Productivity; Buddhism; Meditation. Introdução

De acordo com Etzioni (1967), a sociedade moderna é uma sociedade de organizações, uma vez que os indivíduos nascem em organizações, sua educação é realizada por organizações e é nelas onde passam a vida trabalhando. Ainda, até no momento mais vulnerável da existência humana, o leito de morte, é em uma organização em que nos extinguimos. Sendo assim, para o autor, a sociedade moderna depende constantemente das organizações.

Apoiado no pensamento de Etzioni (1967), Solé (2004), ao analisar determinados campos comuns da existência humana como a alimentação, o vestuário, os locais de entretenimento e/ou lazer, constata que são as empresas que fornecem a conduta de vida dos indivíduos. A reflexão sobre este ponto é simples: os indivíduos trabalham em empresas com a expectativa de lograr um salário, o qual permite comprarem mercadorias, visando à satisfação de suas necessidades. Com isso, boa parte daquilo que fornece sentido a nossa vida, inclusive alguns dos nossos sonhos (de sucesso) e medos (do fracasso), são mercadorias produzidas essencialmente por empresas (RODRIGUES; SILVA; DELLAGNELO, 2014). Em síntese, para Solé (2004), nosso mundo não é o mundo das organizações, mas sim o mundo das empresas, pois elas nos divertem, nos alimentam, nos vestem, nos educam, permitem a nossa existência através do trabalho, fornecem sentido à nossa vida, organizam nosso tempo, nos dizem o que pensar, impactam na nossa saúde (mental e física), etc.

Segundo os autores Franz e Rodrigues (2019) as sociedades modernas experimentaram inúmeras transformações que levaram ao estabelecimento de novas relações sociais, novas formas de atuar no mundo, novos conhecimentos e crenças, os quais colaboraram para inserir a empresa como a organização central no nosso mundo. Este mundo, que tem a empresa como organização de referência, é denominado Mundo-Empresa (SOLÉ, 2004).

Diretamente relacionado à noção de Mundo-Empresa, também podemos perceber um outro fenômeno no qual o discurso empresarial, assentado na ideia de eficiência, qualidade e resultados, é amplamente disseminado e incorporado por indivíduos e organizações (RODRIGUES; SILVA; DELLAGNELO, 2014). O processo de empresarização é 


\section{Revista Cadernos de Economia}

Universidade Comunitária da Região de Chapecó -Unochapecó

justamente isso: a generalização da ideia de empresa sobre indivíduos e demais organizações (RODRIGUES; SILVA, 2019).

Em decorrência do avanço da ideia de empresa sobre tudo e todos, Rodrigues, Silva e Dellagnelo (2014) afirmam que tentar encontrar uma definição para o que pertence ou não ao âmbito econômico tornou-se tecnicamente impossível, uma vez que esferas como, por exemplo, a arte, o lazer e a religião foram marcados ou condicionados por e para objetivos econômicos. Especificamente no nível organizacional, podemos evidenciar uma série de estudos orientados à análise do processo de empresarização na área da saúde, da educação e da cultura, como, por exemplo, os trabalhos de Borges, Barcelos e Rodrigues (2018), Rodrigues e Silva (2019) e Rodrigues, Silva e Dellagnelo (2014), respectivamente.

Outro espaço que também está submetido a uma lógica empresarial é o da religião. Os trabalhos de Serra (2005) e Gonçalves, Serra e Costa (2007), empenharam-se em analisar o que esses autores denominaram de "empresarização do sagrado", a partir de uma discussão que buscou verificar a existência de uma vinculação entre o processo de empresarização e as mudanças na estrutura organizacional de igrejas evangélicas brasileiras. Nesse sentido, percebemos um processo no qual premissas que antes eram estranhas a esse modelo empresarial, são hoje apropriadas pelas mais distintas organizações com a finalidade de elevar o nível de produtividade, de eficiência e de retorno financeiro.

Adotando a ideia de sentimentos como pertencimento, união e afinidade, a religião é capaz de unir diferentes grupos que integram uma sociedade. Muitos pesquisadores acreditam que a religião intervém na visão de mundo dos indivíduos, uma vez que aquela muda hábitos e valores, transfigurando assim as atitudes e conduta de vida destes. Dessa forma, partindo de uma hipotética promessa pela busca da felicidade, de um propósito de vida e do alívio da angústia do homem, o budismo entra como peça fundamental para a análise da atual pesquisa.

Para Weber (1958) o budismo é uma das principais religiões do mundo. A busca pela salvação no budismo se distingue de outras religiões como por exemplo, o cristianismo, o judaísmo e o islamismo, pelo fato dela não estar centrada na razão, mas sim em princípios espirituais, tidos como "mágicos" ou de "salvação", sendo eles a meditação e as preces. Ainda segundo o autor, o budismo pode ser caracterizado como uma religião "apolítica" uma vez que a salvação é um ato pessoal de cada indivíduo, tendendo remetê-lo a uma busca fora da sociedade. 


\section{Revista Cadernos de Economia}

Universidade Comunitária da Região de Chapecó -Unochapecó

De acordo com Harvey (2012) o budismo não se trata apenas de uma religião, mas também de um sistema ético e filosófico, originário do norte da Índia. Seu surgimento compreende o século VI a.c. inicialmente praticado por Sidarta Gautama (Buda). Conforme o autor, Buda não deve ser representado por uma pessoa, já que seu significado exprime aquele que despertou, ou seja, aquele que transcendeu a condição humana e atingiu o caminho do meio, a iluminação.

A partir dos sermões de Buda, o budismo foi conduzido por todo o Oriente e, ao se mesclar com a cultura de cada região, criaram-se correntes diversas de pensamento budista, como o budismo indiano, o chinês, o japonês e o tibetano. Em seu início, foi difundido por monges mendicantes os quais se abstiveram dos prazeres do mundo e, por não possuírem local estável para moradia, eram considerados nômades. Apenas esses monges eram plenos participantes da comunidade religiosa; todos os outros eram leigos de condição inferior: objeto; e não sujeitos da religiosidade (WEBER, 1965).

No século XX, o budismo chega no Brasil com a vinda dos imigrantes japoneses que, ao coabitar esta nova realidade, se adaptaram e se aculturaram aos costumes do país. $\mathrm{Na}$ década de 1990, o budismo passou a ter uma maior circulação nos canais de mídia do país, devido, provavelmente, ao fato de que, em 1989, Tenzin Gyatso, o XIV Dalai Lama, ganhou o prêmio Nobel da Paz. Apesar de ser compreendida como uma filosofia que, teoricamente, é alheia a qualquer questão econômica, é evidente a existência de um processo de apropriação e, nos últimos anos, um constante incentivo à adoção de práticas budistas, muito em decorrência dos próprios prejuízos causados pelo avanço dessa lógica empresarial, como o estresse, a ansiedade, o esgotamento, dentre inúmeros outros sintomas ocasionados por essa forma de organização.

A partir disso, o presente artigo aborda um caminho um pouco diferente das pesquisas a respeito de empresarização e religião. Ele não está orientado à análise da incorporação de técnicas empresariais no espaço religioso. Ao contrário, o objetivo é evidenciar a incorporação de práticas religiosas no espaço empresarial e a transmutação de seus significados. Para tanto, fazendo a vinculação da influência do processo de empresarização com o budismo, este trabalho analisou reportagens, retiradas da revista EXAME, que apresentavam conteúdo relacionado ao tema, evidenciando a constante intervenção do modelo empresarial sobre as organizações culturais. 


\section{Revista Cadernos de Economia}

Universidade Comunitária da Região de Chapecó -Unochapecó

Do ponto de vista da contribuição teórica, a atual pesquisa auxilia na área de estudos organizacionais por meio da compreensão e entendimento crítico acerca das mudanças que vêm ocorrendo nas organizações culturais devido a incorporação de ferramentas empresariais. Análises que compõem a relação entre o budismo e a empresarização ainda não foram exploradas, o que mostra a potencial importância deste trabalho. Ademais, como meio para alcançar o objetivo proposto, o texto está disposto em quatro partes. Apresentamos a introdução e após os procedimentos metodológicos. Em seguida, trazemos as análises das reportagens pesquisadas. Por fim, encerramos com as devidas considerações finais.

\section{Metodologia}

Levando em consideração a proposta deste artigo, optamos por adotar uma abordagem predominantemente qualitativa. De acordo com Godoy (1995) esta abordagem auxilia a identificar as causas das transformações e, por conseguinte, ajuda a descrever suas implicações. Para Vieira e Zouain (2006) o método qualitativo não somente permite uma maior flexibilidade ao pesquisador, no que tange à conciliação entre o referencial teórico e a temática do trabalho, como também proporciona, mais satisfatoriamente, um entendimento em relação a um evento sem que haja dissociação de seu contexto.

Para realizar essa primeira aproximação com o tema, utilizamos dados secundários, precisamente, aqueles disponíveis em reportagens da revista EXAME. Tendo em vista a variada gama de caminhos de pesquisa (mídia eletrônica), a escolha do objeto deu-se a partir da constatação de que tal revista de negócios apresenta maior visibilidade e acessibilidade no país. Criada em 1967 e editada pela Editora Abril, a revista apresenta uma tiragem de aproximadamente cem mil exemplares por quinzena e seu site recebe cerca de quinze milhões de visitas por mês (EXAME, 2019).

Sendo o objetivo deste texto demonstrar como o meio empresarial está se apropriando das práticas budistas, realizamos uma pesquisa sobre budismo e mundo empresarial na revista EXAME, utilizando as seguintes palavras-chave: budismo, meditação, produtividade, empresas e felicidade. Nessa busca foram encontradas cerca de 60 (sessenta) reportagens entre os anos de 2008 e 2019 que tratavam de pelo menos dois dos termos citados anteriormente. Por se tratar de uma grande quantidade de material, optamos por selecioná-los e analisá-los preliminarmente, com o intuito de identificar eventuais 
redundâncias e, também, para evitar o risco de coletar material em uma quantidade além da que seria efetivamente utilizada.

Após a leitura dos materiais, foram selecionados 5 (cinco) reportagens que tratavam, de forma mais contundente, do budismo e das práticas budistas apropriadas pelas empresas, conforme ilustrado a seguir (Quadro 1).

\begin{tabular}{|l|c|c|}
\hline \multicolumn{1}{|c|}{ Título da Reportagem } & Data de Publicação & Autor(es) \\
\hline $\begin{array}{l}\text { "4 benefícios que a } \\
\text { meditação traz para sua } \\
\text { carreira" }\end{array}$ & $28 / 08 / 2012$ & Camila Pati \\
\hline $\begin{array}{l}\text { "Seja mais produtivo, } \\
\text { mantendo o foco, como } \\
\text { quer Goleman" }\end{array}$ & $16 / 01 / 2014$ & $\begin{array}{c}\text { José Eduardo Costa e } \\
\text { Nataly Pugliesi }\end{array}$ \\
\hline $\begin{array}{l}\text { "Parar, respirar, meditar. } \\
\text { Até trabalho" }\end{array}$ & $07 / 08 / 2014$ & Marcia Di Domenico \\
\hline $\begin{array}{l}\text { "Como a meditação } \\
\text { ajuda a ter sucesso nos } \\
\text { negócios" }\end{array}$ & $14 / 09 / 2016$ & Mariana Desidério \\
\hline $\begin{array}{l}\text { "Vivo quer que } \\
\text { funcionários (e clientes) } \\
\text { meditem" }\end{array}$ & $22 / 06 / 2017$ & Tatiana Vaz \\
\hline
\end{tabular}

Quadro 1 - Reportagens selecionadas e analisadas

As reportagens foram examinadas a partir de uma abordagem descritivainterpretativa, ou seja, efetuamos a descrição e a associação à perspectiva teórica utilizada. De acordo com Triviños (1987), tal método visa descrever com precisão os fatos e fenômenos da realidade investigada. Porém, como estas realidades estão repletas de significados atribuídos pelo ambiente, bem como são fruto de uma visão subjetiva, descrevêlas apenas não basta. Torna-se necessário, portanto, a interpretação das informações levantadas para que seja captada, não somente a aparência dos fenômenos, como também a sua essência (TRIVIÑOS, 1987).

\section{Análises das reportagens}

Neste momento, discorreremos sobre como as empresas estão se apropriando dos ensinamentos budistas, por meio do uso de práticas que antes eram vistas somente sob a perspectiva do crescimento do indivíduo. A verificação dessa afirmação pode ser vista 
Revista Cadernos de Economia

Universidade Comunitária da Região de Chapecó -Unochapecó

comumente na mídia, uma vez que essas práticas estão sendo cada vez mais empossadas por um universo que, até então era distinto da filosofia budista, sendo este o empresarial. Elas passam a ser trabalhadas e adaptadas para que sirvam aos propósitos desse novo ambiente, o qual busca essencialmente aumento da produtividade e redução de conflitos por meio do controle do estresse e da ansiedade.

$\mathrm{Na}$ reportagem intitulada "4 benefícios que a meditação traz para sua carreira"; Camila Pati (2012) disserta acerca da democratização da prática de meditação, uma vez que qualquer indivíduo, sem experiência prévia, pode envolver-se nesta nova "aventura". Segundo a autora, a meditação auxilia no controle da mente e nos mantém no momento presente, o que é percebido por meio dos benefícios experimentados pelos praticantes, os quais ultrapassam o campo pessoal e são também visíveis em sua carreira. Ao explanar quanto aos benefícios, a autora utiliza a seguinte frase: "Confira o que você também pode ganhar ao aderir à prática”, e, fazendo uma breve análise, entendemos que uma provável explicação para a escolha desta expressão, pode ser trazida a partir do que Solé (2004) caracteriza como sendo a crescente influência dos pressupostos empresariais ante os seres humanos. De fato, apoiando-se em preceitos de produtividade, desempenho e resultados, a empresa tem se tornado o modelo que serve de exemplo para todas as atividades humanas. Nesse processo, torna-se visível a apropriação de linguagens, métodos e práticas, os quais são adaptados e adequados para uma nova realidade, evidenciando o forte impacto dessa nova configuração sobre tudo e todos.

Para Pati (2012) a meditação proporciona benefícios como concentração e atenção, criatividade e diminuição do estresse. A autora menciona que a meditação possibilita que haja maior facilidade na manutenção dos pensamentos focados no presente, ou seja, tristezas do passado e angústias do futuro são dispersadas com o treinamento da mente. Após o término da prática, o aluno carrega consigo estas habilidades, tanto em sua vida particular como no ambiente de trabalho, tornando possível assim manter a atenção total na tarefa e ser mais produtivo (PATI, 2012). Do mesmo modo, a autora cita a diminuição do estresse como uma das consequências da utilização da meditação no trabalho, uma vez que hormônios são liberados durante a prática, como a endorfina e a serotonina, responsáveis pela sensação de prazer e bem-estar no organismo. Ainda, segundo ela, ao sentirem-se melhor e livres do estresse, as pessoas tendem a ficar menos doentes, o que resulta na diminuição do absenteísmo no trabalho. Ela constata que, ao incorporar a meditação como artífice para a 


\section{Revista Cadernos de Economia}

Universidade Comunitária da Região de Chapecó -Unochapecó

obtenção de um ambiente de trabalho mais agradável, as empresas inserem a prática com a intenção de minimizar o esgotamento físico e mental dos funcionários, esgotamentos estes causados pela própria organização. Ao aderir à prática, os níveis de estresse são reduzidos, o que gera maior satisfação e contentamento, ocasionando menor índice de faltas por motivos de adoecimento e/ou indisposição.

Ao final da reportagem, Pati (2012) menciona que a meditação traz uma sensação de tranquilidade e relaxamento, uma vez que ocorre a diminuição dos batimentos cardíacos e, com isso, novos estados mentais surgem, propiciando uma serenidade que é peça fundamental para quem busca maior criatividade. Sendo assim, torna-se evidente que as organizações incorporam tal ferramenta com o objetivo de melhorar a capacidade cognitiva e inovadora, além de aumentar os níveis de produtividade.

A segunda reportagem, José Eduardo Costa e Natalay Pugliesi (2014) em "Seja mais produtivo, mantendo o foco, como quer Goleman" baseando-se nas ideias de Daniel Goleman, psicólogo americano, aponta sobre a capacidade de manter o foco ser essencial para obter altos índices de produtividade no trabalho. Além disso, o autor afirma que a atenção é como um músculo mental, podendo ser treinada e com isso fortificando as conexões neurológicas, ou seja, por meio da meditação pode-se treinar a capacidade de manter a atenção.

Segundo os autores, a ideia central que Goleman buscar transmitir no texto é a seguinte: com o uso da meditação dentro de uma instituição, o único propósito são as pessoas serem capazes de manter a concentração e gerar resultados e, ainda, segundo o psicólogo, isso é muito proveitoso, uma vez que quando há o foco na tarefa há, por óbvio, alto desempenho e aumento da performance no trabalho. Dessa forma, esse pensamento vai na direção contrária do que a meditação em si representa, pois no momento em que se busca unir uma prática budista a uma técnica empresarial, o fundamento por trás dessa prática é subvertido. Percebemos, então, que a empresa além de ser o referencial copiado por outras organizações, também está buscando influenciar em novos comportamentos, o que propicia o aprimoramento de atitudes que estas desejam.

No artigo intitulado "Parar, respirar, meditar. Até no trabalho"; Márcia Di Domenico (2014) discorre relativamente sobre as vantagens da prática de meditação em ambientes corporativos, dentre elas: a melhora dos relacionamentos entre os departamentos, o alívio do estresse e da ansiedade e a regulação dos impulsos emocionais. Conforme a reportagem, $E$ - 


\section{Revista Cadernos de Economia}

Universidade Comunitária da Região de Chapecó -Unochapecó

bay, Facebook e Google são exemplos de grandes corporações que utilizam programas de mindfulness, palestras com mestres budistas e também disponibilizam espaços próprios para meditar. É importante observar que práticas como essas podem significar uma melhora nos processos atencionais, em que a mente se torna mais alerta, o que poderá influenciar na produtividade dos funcionários (DI DOMENICO, 2014). Nessa perspectiva, observamos que ao utilizar a meditação, as grandes corporações inserem estratégias que culminam na manipulação de determinadas características que podem ser consideradas virtuosas, provavelmente pelo fato de interferirem nos padrões de desempenho dos funcionários.

A reportagem traz também, alguns estudos relacionados às mudanças que a meditação produz nas estruturas e funções cerebrais. Elisa Kozasa, bióloga do Instituto do Cérebro do Hospital Israelita Albert Einstein, comparou o cérebro de pessoas que meditam periodicamente e o cérebro de pessoas que não meditam. Segundo ela, estas últimas precisam ativar mais regiões para realizar a mesma tarefa, ou seja, é como se o cérebro de quem medita fosse mais eficiente. Outro estudo conduzido por neurocientistas do Instituto de Tecnologia de Massachusetts (MIT) e da Universidade de Harvard revelou que com a prática meditativa diária, desenvolvemos uma capacidade de controlar um tipo específico de onda cerebral ativada por informações que geram distração e dissipam a atenção. Isto significa que, a meditação desenvolve o foco. Como consequência da utilização da meditação como ferramenta que auxilia na procura/manutenção do foco, as organizações buscam que os funcionários sejam capazes de se autocontrolar, resultando em uma diminuição de intempéries no ambiente de trabalho.

Em relação a matéria denominada "Como a meditação ajuda a ter sucesso nos negócios"; Mariana Desidério (2016) apresenta o impacto que a meditação proporciona no indivíduo, mais especificamente nos benefícios gerados dentro das organizações. $\mathrm{O}$ ato de meditar quando utilizado por empreendedores, traz ainda mais vantagens, uma vez que além de manter a vida em equilíbrio, a prática os ajuda a ter mais sucesso nos negócios (DESIDÉRIO, 2016). Ainda segundo a autora, os benefícios vão desde a maior produtividade até o aumento da capacidade de resolver conflitos. Ela menciona alguns proveitos advindos dessa atividade, como por exemplo, manutenção do foco, gestão de tempo, bem-estar da esquipe, gestão financeira, capacidade de liderança e criatividade. À vista disso, percebemos que os indivíduos estão aderindo à meditação baseados em um discurso que está completamente inserido em uma lógica empresarial. Dessa maneira, ocorre 
Revista Cadernos de Economia

Universidade Comunitária da Região de Chapecó -Unochapecó

uma generalização dos preceitos organizacionais os quais, muitas vezes, são considerados sinônimos de sucesso e satisfação. Outrossim, verificamos que a utilização da meditação se torna um meio para que as empresas logrem resultados em todas as suas camadas, já que os funcionários passam a se comportar de acordo com o que lhes é orientado.

Na última reportagem, um exemplo de empresarização no cenário brasileiro pode ser observado na maior telefonia do Brasil, a Vivo/Telefônica. Tatiana Vaz em "Vivo quer que funcionários (e clientes) meditem" apresenta que no ano de 2017 foi criada uma sala de meditação na sede da empresa em São Paulo e um aplicativo foi desenvolvido com a intenção de proporcionar relaxamento e controlar a ansiedade dos funcionários. Aliada a uma campanha de marketing, a realização de uma sala de meditação incentiva o autoconhecimento, posto a ideia de transformar a Vivo em uma empresa cada vez mais humana, aberta e democrática (VAZ, 2017). Contraditoriamente, o uso dessa prática dentro de qualquer empresa ajuda no autocontrole dos funcionários fazendo os conflitos gerados pelo estresse, a pressão e a ansiedade serem apenas ocultados. Consequentemente, os funcionários desenvolvem certas habilidades e trazem mais rendimentos para a empresa, mesmo não percebendo essa mudança e, quando percebem, acreditam estar crescendo e evoluindo junto à organização.

Observamos, assim, o evidente processo de apropriação realizado pelas empresas, em que a meditação, principalmente, é utilizada com o intuito de otimizar a produtividade dos trabalhadores e, com isso, gerar maior lucratividade. Para tanto, ficou claro que para a obtenção desse resultado, as empresas buscam que os funcionários sejam cada vez mais capazes de se autocontrolarem, ou seja, a adoção da meditação faz com que eles produzam mais, com foco na tarefa e, ainda, reduzam seus níveis de estresse e ansiedade.

De posse dessas argumentações, é possível deduzir que as práticas budistas, inclusive os "personagens" que se utilizam dos propósitos do budismo, tornam-se comercializáveis. Nesse sentido, a aproximação com as reportagens estudadas nos possibilitou constatar que as empresas estão passando por um processo crescente de apropriação e deturpação dos conhecimentos da filosofia budista. Entretanto, os pressupostos em que esta se baseia vão na direção contrária do que propõe a lógica empresarial, visto que nesta última o foco é exclusivamente e/ou majoritariamente a obtenção de lucro e produtividade.

\section{Conclusão}


Demonstramos neste artigo as transformações que vem ocorrendo diante dos novos modelos de gestão e das novas práticas que as organizações estão dispostas a adotar com a finalidade única de tornarem-se mais desenvolvidas. Através de uma pesquisa com abordagem qualitativa, procuramos ilustrar, por meio da análise da literatura e das reportagens, como a lógica empresarial evoluiu nas últimas décadas com a inserção de mecanismos (práticas budistas) no espaço empresarial e a transmutação de seus significados.

Podemos perceber como as empresas se beneficiam da meditação como uma aliada para completar as lacunas que o próprio modelo empresarial ocasiona, como a ansiedade, a frustação e principalmente a exaustão. Por meio da utilização da meditação, fica comprovado que as empresas buscam meramente a maior produtividade dos funcionários, alcançada através de um discurso de autocontrole e equilíbrio dos trabalhadores. Em outras palavras, os indivíduos são apresentados à prática somente com a intenção de obter benefícios relacionados a preceitos mercadológicos e, como consequência, as empresas se beneficiam de diversas maneiras.

Constatamos que o resultado mais desejado pelas organizações está vinculado ao aumento da produtividade dos funcionários. Para as empresas, ao introduzir a meditação na rotina de trabalho, o funcionário reduz seus níveis de estresse e ansiedade, causando uma regulação de seus impulsos emocionais e assim, obtendo maior concentração e foco nas tarefas. Logo, notamos uma diminuição no tempo de execução das mesmas e, por óbvio, um acréscimo na capacidade produtiva dos envolvidos, resultando em excelentes proveitos para a empresa.

Assim, os gestores passam a atuar fundamentalmente na construção de dispositivos cada vez mais sutis de controle, nos quais, além de disseminar o referencial para outras organizações, há o compartilhamento de uma mesma visão de mundo (empresa) para com os indivíduos, pois influencia em novas condutas e atitudes desejadas pelas mesmas. Frente aos resultados obtidos, procuramos analisar, neste estudo, como as empresas estão se transformando e adentrando em campos que antes eram inimagináveis obterem conciliação.

Cabe mencionar que o inverso também está ocorrendo, em virtude de, cada vez mais, o budismo estar sendo empresariado. Essa afirmação torna-se válida a partir de uma breve análise do crescente número de livros que vêm sendo escritos por monges e monjas budistas e da ampla disseminação de cursos e palestras motivacionais (autoajuda) promovidos pelos 
Revista Cadernos de Economia

Universidade Comunitária da Região de Chapecó -Unochapecó

mesmos. Além disso, é notório o aumento progressivo, em inúmeros canais de informação, da aparição de grandes expoentes budistas, os quais muitas vezes são vistos, principalmente, em sites de coaching e revistas de negócios. Nesse caso, percebemos que o discurso propagado pelos monges, em suma, é feito utilizando uma linguagem de fácil compreensão, onde frequentemente é citada a meditação como um instrumento para quem busca relaxamento. Inferimos então que ao elucidarmos a respeito dos benefícios da meditação, os praticantes estão sujeitos a um ciclo, em que eles usufruem de uma breve fase de relaxamento, mas posteriormente voltam ao status anterior de turbulência, seja em sua vida profissional ou pessoal.

Muitas questões ainda estão em aberto no que diz respeito ao avanço da lógica empresarial sobre as práticas budistas, provavelmente em decorrência da não existência de um profundo levantamento de pesquisas que abarcam o tema explorado. Sugerimos que sejam realizados estudos que possibilitem analisar a percepção dos trabalhadores acerca da incorporação da meditação; analisar as organizações que inseriram e/ou estão inserindo a meditação em sua composição; verificar como as empresas distorcem os ensinamentos budistas e como os indivíduos os interpretam.

\section{Referências Bibliográficas}

BORGES, J. C. P.; BARCELOS, M.; RODRIGUES, M. S. Empresarização da saúde pública: o caso da EBSERH. Revista Pensamento Contemporâneo em Administração, v.12, n.4, p.75-90, out/dez. 2018.

COSTA, J. E.; PUGLIESI, N. Seja mais produtivo, mantendo o foco, como quer Goleman. Revista Exame, São Paulo, 16 jan. 2014. Online. Disponível em: https://exame.abril.com.br/carreira/seja-mais-produtivo/ Acesso em 02 ago. 2019.

DESIDÉRIO, M. Como a meditação ajuda a ter sucesso nos negócios. Revista Exame, São Paulo, 14 set. 2016. Online. Disponível em: https://exame.abril.com.br/pme/como-ameditacao-ajuda-a-ter-suecsso-nos-negocios/ Acesso em 14 mar. 2020.

DI DOMENICO, M. Parar, respirar, meditar. Até no trabalho. Revista Exame, São Paulo, 07 ago. 2014. Online. Disponível em: https://exame.abril.com.br/carreira/a-meditacaoprodutiva/ Acesso em 02 ago. 2019.

ETZIONI, A. Organizações Modernas. São Paulo: Pioneira, 1967.

EXAME. São Paulo, 2019. Disponível em: <https://exame.com/sobre/>. Acesso em 15 mar. 2020. 
Revista Cadernos de Economia

Universidade Comunitária da Região de Chapecó -Unochapecó

FRANZ, A. H.; RODRIGUES, M. S. Repensando o processo de empresarização: a inserção de um olhar de inspiração foucaultiana. Revista grifos, n.47, 2019.

GODOY, A. S. Pesquisa qualitativa: tipos fundamentais. Revista de Administração de Empresas, v.35, n.3, p.20-29, 1995.

GONÇALVES, J. C. de S.; SERRA, A. R. C.; COSTA, C. E. S. A empresarização do sagrado: um estudo sobre a estruturação de igrejas protestantes brasileiras. Revista Eletrônica de Ciência Administrativa, v.6, n.2, p. 1-14, 2007.

HARVEY, P. An introduction to buddhism: teachings, history and practices. 2. ed. New York: Cambridge University Press, 2012.

PATI, C. 4 benefícios que a meditação traz para sua carreira. Revista Exame, São Paulo, 28 ago. 2012. Online. Disponível em: https://exame.abril.com.br/carreira/4-beneficios-que-ameditacao-traz-para-sua-carreira/ Acesso em 14 mar. 2020.

RODRIGUES, M. S.; SILVA, R. C. A estrutura empresarial nos clubes de futebol. Organizações \& Sociedade, Salvador, v.16, n.48, 2009.

RODRIGUES, M. S.; SILVA, R. C.; DELlaGNElO, E. H. L. O processo de empresarização de organizações culturais brasileiras. Revista Pensamento Contemporâneo em Administração. Rio de Janeiro, v.8, n.1, p.66-85, jan/mar. 2014.

RODRIGUES, M. S.; SILVA, R. C. da. Nova república, novas práticas: uma análise do processo de empresarização do ensino superior no Brasil (1990-2010). Revista de Estudos Organizacionais e Sociedade (Farol), v.6, n.15, p.176-218, 2019.

SERRA, A. R. C. A empresarização do sagrado: um estudo sobre a estruturação de igrejas dos protestantismos brasileiros. 2005. 195f. Dissertação (Mestrado em Administração) Programa de Pós-Graduação em Administração, Universidade Federal de Santa Catarina, Florianópolis, 2005.

SILVA, R.; VIEIRA, M. M. F.; DELLAGNELO, E. L.; CARVALHO, C. A. Para além da empresa: por outras possibilidades de teorizar sobre organizações. Working Paper. Porto Alegre, Observatório da Realidade Organizacional, 2007.

SOLÉ, A. A. ¿Qué es una empresa? Construcción de un idealtipo transdisciplinario. Working Paper. Paris, 2004.

L'enterprisation du monde. In: CHAIZE, J.; TORRES, F. Repenser l'entreprise: Saisir ce qui commence, vingt regards sur une idée neuve. Paris: Le Cherche 2008.

TRIVIÑOS, A. N. S. Introdução à pesquisa em ciências sociais: a pesquisa qualitativa em educação. São Paulo: Atlas, 1987. 
Revista Cadernos de Economia

Universidade Comunitária da Região de Chapecó -Unochapecó

VARGAS, L. M.; RODRIGUES, M. S. A empresarização dos centros de tradições gaúchas: uma análise das relações de concorrência e de consume. Revista Gestão Organizacional, Chapecó, v.12, n.4, p.3-24, set./dez. 2019.

VAZ, T. Vivo quer que funcionários (e clientes) meditem. Revista Exame, São Paulo, 23 jun. 2017. Online. Disponível em: https://exame.abril.com.br/negocios/vivo-quer-quefuncionarios-e-clientes-meditem/ Acesso em 02 ago. 2019.

VIEIRA, M. M. F.; ZOUAIN, D. M. (orgs.). Pesquisa qualitativa em administração. $2^{\mathrm{a}}$ ed. Rio de Janeiro: FGV, 2006.

WEBER, M. The religion of India: the sociology of Hinduism and Buddhism. Free Press, 1958.

. The Sociology of Religion. London: Methuen, 1965. 